\title{
The Circulating Levels of Cardiac Natriuretic Hormones in Healthy Adults: Effects of Age and Sex
}

\author{
Aldo Clerico*, Silvia Del Ry, Silvia Maffei, \\ Concetta Prontera, Michele Emdin and \\ Daniela Giannessi \\ Institute of Clinical Physiology, University of Pisa, Pisa, Italy
}

In order to study the relationships between sex hormones, aging, and circulating levels of cardiac natriuretic peptides and to define reference values for atrial natriuretic peptide (ANP) and brain natriuretic peptide (BNP) assays, we measured the plasma levels of cardiac natriuretic peptides in a large group of healthy adults divided according to age and sex. We studied 216 healthy subjects of both sexes (109 men and 107 women) with age ranging from 20 to 77 years (mean $43.2 \pm 14.8$ years). All subjects were non-obese and had normal arterial blood pressure; they were free from acute diseases, including asymptomatic heart disease. Highly sensitive and specific IRMA methods were used to measure plasma ANP and BNP. The mean ANP value in healthy adult subjects of both sexes was $17.8 \pm 10.9$ $\mathrm{pg} / \mathrm{ml}$ with no significant difference between men $(16.7 \pm 10.0 \mathrm{pg} / \mathrm{ml})$ and women $(18.8 \pm 11.7 \mathrm{pg} / \mathrm{ml})$. The mean BNP value in healthy adult subjects of both sexes was $9.9 \pm 9.0 \mathrm{pg} / \mathrm{ml}$ with a significant difference $(p<0.0001)$ between men $(7.7 \pm 7.1 \mathrm{pg} / \mathrm{ml})$ and women $(12.2 \pm 10.2 \mathrm{pg} / \mathrm{ml})$. There was a weak linear relationship between age and either ANP $(r=0.350, p<0.0001)$ or BNP $(r=0.254, p=0.0002)$ values. When the circulating levels of cardiac natriuretic hormones, and age and sex were analyzed by multiple stepwise regression analysis, both age and sex significantly and independently contributed to the regression. Our study indicates independent positive effects of aging and female sex hormones on ANP and BNP levels in healthy adult subjects. These effects should be taken into account in the calculation of appropriate reference values for cardiac natriuretic hormones. Clin Chem Lab Med 2002; 40(4):371-377

Key words: Atrial natriuretic peptide (ANP); Brain natriuretic peptide (BNP); IRMA; Sex steroid hormones (female).

Abbreviations: ANF, atrial natriuretic factor; $A N P$, atrial natriuretic peptide, BNP, brain natriuretic peptide; CNP, C-type natriuretic peptide; IRMA, immunoradiometric assay; RIA, radioimmunoassay.

*E-mail of the corresponding author: clerico@ ifc.pi.cnr.it

\section{Introduction}

Human cardiomyocytes produce and secrete a family of related peptide hormones (cardiac natriuretic hormones) which have potent diuretic, natriuretic and vascular smooth muscle-relaxing effects. They are involved in complex interactions with the hormonal and nervous systems (1-3). Cardiac natriuretic hormones include atrial natriuretic peptide or factor (usually indicated as ANP, more properly designated as human $\mathrm{ANF}_{(99-126)}$ or ANF) (4), brain natriuretic peptide (BNP) and their related peptides. Other natriuretic peptides such as C-type natriuretic peptide (CNP) and urodilatin, structurally related to the ANP/BNP peptide family, are not produced and secreted by cardiomyocytes but by other tissues (1-3).

Cardiac natriuretic peptides are greatly increased in diseases characterized by an expanded fluid volume $(1-3,5)$. In particular, the importance of measuring the circulating levels of these peptide hormones in the classification of patients with heart failure and/or in predicting their mortality/survival rates has been recently reported (1-4). As a result, the assay of circulating levels of cardiac natriuretic peptides is now considered to be a useful marker of myocardial function (1-3, 5).

Age and sex are two potent non-modifiable cardiovascular risk factors (6). The incidence of cardiovascular disease increases progressively with age. On the other hand, the incidence of cardiovascular disease is significantly lower in women during their child-bearing years than in men; after menopause this difference disappears (6-8). Furthermore, several studies have suggested a cardioprotective role for estrogen replacement therapy in postmenopausal women (7,9-12).

The relationship between cardiac natriuretic hormones (ANP and BNP) and female steroid sex hormones and/or age has been poorly investigated in humans $(2-3,5,7,13-18)$. Higher circulating levels of ANP and/or BNP in women than in men were incidentally observed in some studies (13-16). Moreover, to our knowledge, only two studies have been performed in order to specifically evaluate the influence of age on circulating levels of cardiac natriuretic peptides in healthy adults $(17,19)$.

This lack of studies on the influence of age and sex hormones on the ANP/BNP system could be due to methodological problems. First, it is difficult to find a reliable number of truely healthy subjects over 65 years of age, since approximately $85 \%$ of the people over the age of 65 suffer from one or more chronic conditions (20). Other methodological problems are related to the very low plasma concentrations of cardiac 
natriuretic peptides in normal adults (on average 10-20 $\mathrm{pg} / \mathrm{ml}$ ), often below the sensitivity level of radioimmunoassay (RIA) methods generally used to measure these hormones $(3,5)$.

The reference values for ANP and BNP commonly used in pathophysiological studies, as well as in clinical practice, do not take into account possible effects of age and sex. This is important because it is well known that the incidence of cardiac diseases also increases progressively with age $(12,13)$. Indeed, the majority of patients with cardiac disease are older than 50 years; therefore, the circulating levels of cardiac natriuretic hormones of these patients should be compared with reference values calculated from a group of normal subjects of comparable age.

In order to study the relationships between sex hormones and circulating levels of cardiac natriuretic peptides, we measured plasma levels of cardiac natriuretic peptides by means of highly sensitive and specific immunoradiometric assay (IRMA) methods (previously set up in our laboratory) $(15,17,21)$ in a large group of healthy adults divided according to age and sex.

\section{Subjects, Materials and Methods}

\section{Subjects}

We studied 216 healthy subjects (109 men and 107 women) with age ranging from 20 to 77 years (mean $43.5 \pm 14.7$ years); 48 women were postmenopausal and three were perimenopausal, while the other 56 women were normally menstruating women. All subjects were non-obese and had normal arterial blood pressure; they were free from acute diseases, as determined by an interview with a clinician. Furthermore, they denied the use of any drug during the 4 weeks prior to the study. In particular, the group of postmenopausal women denied the use of sex steroid hormones for relief of postmenopausal symptoms, and normally menstruating women denied the use of oral contraceptives. All of them had normal values for the main plasma variables (including creatinine, urea nitrogen, glucose, uric acid, albumin, enzymes, electrolytes and hemoglobin) and normal erythrocyte and leukocyte counts and urine analysis. In the subjects aged $\geq 60$ years a complete cardiological examination, including a standard electrocardiogram and echocardiogram, was also performed in order to exclude asymptomatic heart disease.

The subjects were consuming a typical Mediterranean diet, with free sodium intake ranging from 80 to $180 \mathrm{mmol} / \mathrm{day}$ for the entire population, as determined by an interview with an expert dietician.

Informed consent was obtained from all subjects enrolled in the study.

\section{Assay methods}

Plasma samples

We collected blood samples between 8 am and 9 am following an overnight fast and after 15 min of rest in a sitting position. After collection, blood samples $(10 \mathrm{ml})$ were immediately put into ice-chilled disposable polypropylene tubes containing aprotinin $(500 \mathrm{KIU} / \mathrm{ml}$ of plasma) and EDTA $(1 \mathrm{mg} / \mathrm{ml}$ of plasma). Plasma samples were rapidly separated by centrifugation for $15 \mathrm{~min}$ at $4{ }^{\circ} \mathrm{C}$ and then frozen and stored at $-20^{\circ} \mathrm{C}$ in $1 \mathrm{ml}$ aliquots in polypropylene tubes until assay, which was usually performed within 1 month.

\section{ANP and BNP IRMA}

Plasma ANP and BNP were measured (at least in duplicate) with two-site (sandwich) IRMA methods, which do not require a preliminary step for extraction or purification of plasma samples (direct assay). These IRMA methods use two monoclonal antibodies prepared against two sterically remote epitopes of the human ANP or BNP molecule, of which one is included in the ring structure of the peptide chain. One antibody is coated on the solid phase beads and the other is radiolabeled with ${ }^{125}$. These methods were chosen for this study because of their high degree of sensitivity, accuracy and precision; it is well known that competitive immunoassay methods usually employed for the assay of cardiac natriuretic peptides do not measure the ANP and BNP concentration in the normal range with acceptable precision $(2,3,5)$.

Plasma ANP was measured by an IRMA kit (SHIONORIA ANP, manufactured by SHIONOGI \& Co. Ltd, Osaka Japan) with some modifications, as described in detail elsewhere $(15$, 21). Briefly, the protocol for the assay was as follows. Onehundred $\mu \mathrm{l}$ of standard solution (containing respectively 0,5 , $10,20,60,200,600$ and $2000 \mathrm{pg} / \mathrm{l}$ of synthetic human ANP) or of unknown sample, $200 \mu \mathrm{l}$ of buffer and 1 bead (coated with the first monoclonal anti-ANP antibody) were added to polypropylene assay tubes. After gentle mixing with a vortex, all the tubes were incubated overnight at $4-8^{\circ} \mathrm{C}$. After the content of the tubes was aspirated as completely as possible, the tubes were washed twice with $1 \mathrm{ml}$ of appopriate washing solution provided in the kit; then, $300 \mu$ l of solution containing the labeled monoclonal anti-ANP antibody (about 150,000$200,000 \mathrm{cpm}$ ) was added to each tube. After gentle mixing, all the tubes were incubated $14-20$ hours at $4-8{ }^{\circ} \mathrm{C}$ (second incubation). The contents were then aspirated and washed twice with $1 \mathrm{ml}$ of the washing solution. Finally, the remaining radioactivity bound to the beads was counted for 1-2 min with a gamma scintillation counter.

The assay sensitivity of ANP IRMA was about $2 \mathrm{pg} / \mathrm{ml}$ (if a plasma volume of $100 \mu \mathrm{l}$ was assayed) and the working range was from 10 to $2000 \mathrm{pg} / \mathrm{ml}(15,21)$. It was possible to increase the minimum amount of ANP measured per tube by assaying a volume of plasma greater than $100 \mu \mathrm{l}$ (up to $300 \mu \mathrm{l}$ ), as previously described in detail $(15,21)$. The between-assay precision $(\mathrm{CV} \%)$ was $11.4 \%($ mean $\pm \mathrm{SD}=22.6 \pm 2.6 \mathrm{pg} / \mathrm{ml}, \mathrm{n}=16)$ and $10.7 \%(25.6 \pm 2.7 \mathrm{pg} / \mathrm{ml}, \mathrm{n}=12)$ for the two plasma pools with ANP concentrations in the normal range prepared by pooling together several plasma samples collected from normal subjects, and $8.0 \%(178.6 \pm 14.3 \mathrm{pg} / \mathrm{ml}, \mathrm{n}=16)$ and $6.7 \%(162.2 \pm 10.8$ $\mathrm{pg} / \mathrm{ml}, \mathrm{n}=12$ ) for the other two pools with ANP levels above the normal range prepared by pooling several plasma samples collected from patients with heart failure.

Plasma BNP was measured by an IRMA kit (SHIONORIA BNP, manufactured by SHIONOGI \& Co. Ltd, Osaka Japan), as previously reported in detail $(15,17)$. Briefly, $100 \mu \mathrm{l}$ of standard solutions (containing respectively $0,4,10,40,150,600$, and $2000 \mathrm{pg} / \mathrm{l}$ of synthetic human BNP) or of unknown sample, $200 \mu \mathrm{l}$ of ${ }^{125}$ |-labeled anti-BNP antibody solution and 1 bead (coated with one monoclonal anti-ANP antibody) were added to polypropylene assay tubes. After gentle mixing with a vortex, all the tubes were incubated overnight for 18-22 hours at $4-8^{\circ} \mathrm{C}$. The contents of tubes were then aspirated and washed with $2 \mathrm{ml}$ of the washing solution. It is important to perform the aspiration/washing step at low temperature by keeping the tubes in an ice-bath in order not to perturb the equilibrium of the antigen/antibody complex during this step. Finally, after 
aspiration of the washing solution, the remaining radioactivity bound to the beads was counted for 1-2 min with a gamma scintillation counter.

The assay sensitivity of BNP IRMA was about $2.5 \mathrm{pg} / \mathrm{ml}$ and the working range was from 5 to $2000 \mathrm{pg} / \mathrm{ml}(15,17)$. The between-assay precision was $11.0 \%$ for one plasma pool with BNP concentration in the normal range $(5.10 \pm 0.56 \mathrm{pg} / \mathrm{ml}$, $\mathrm{n}=10$ ) prepared by pooling together several plasma samples collected from normal subjects, and $9.0 \%(58.7 \pm 5.3 \mathrm{pg} / \mathrm{ml}$, $\mathrm{n}=10$ ) for another pool with BNP concentration above the upper limit of normal range prepared by pooling several plasma samples collected from patients with heart failure.

\section{Statistical analysis}

Statistical analysis was carried out on a Power Macintosh G3 personal computer using the Stat-View 5.0.1 program (199298, SAS Institute Inc., SAS Campus Drive, Cary, NC, USA).

Because ANP and BNP values in healthy subjects are not normally distributed, both the original and the logarithmic transformation of data were used for statistical analysis; using the logarithmic transformation of original data the ANP and BNP values approximated better the normal distribution. For comparisons between two independent groups (i.e. men vs. women) the unpaired $t$-test was used, while differences among more than two independent groups were analyzed by ANOVA (Table 1).

ANP or BNP values, considered as dependent variables, and age and sex, considered as independent variables, were also analyzed in a linear multiple regression analysis using a stepwise model (forward selection) without logarithmic transformation of original data. In this type of analysis, sex was considered to be a "dummy" variable, assigning score 1 to men and score 2 to women.

The results are expressed as mean \pm SD unless otherwise stated.

\section{Results}

The mean ANP value in healthy adult subjects of both sexes was $17.8 \pm 10.9 \mathrm{pg} / \mathrm{ml}$ (median $15.5 \mathrm{pg} / \mathrm{ml}$, range

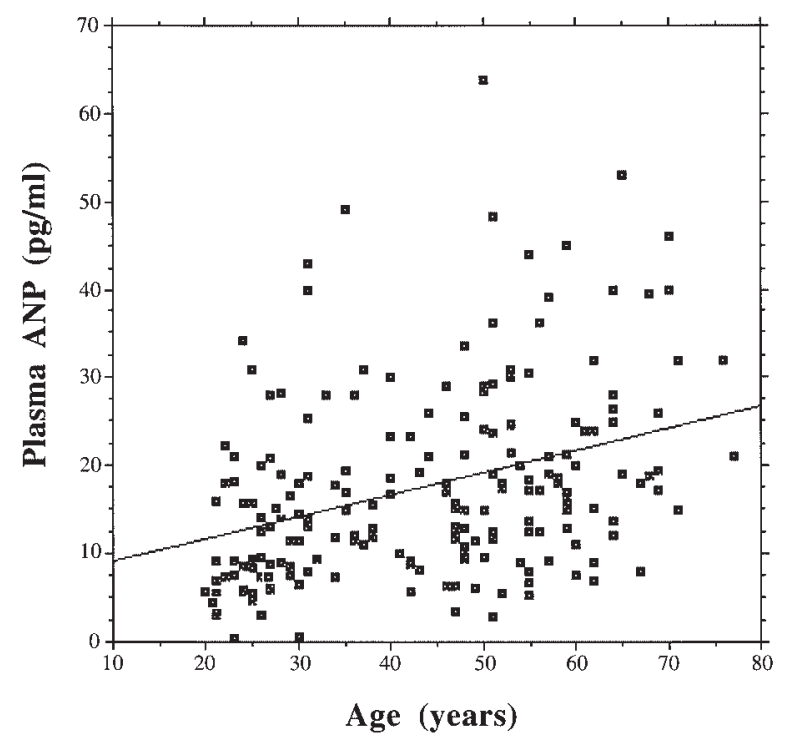

Figure 1 Linear relationship between plasma ANP levels and age in normal men and women. The calculated relationship was: ANP=6.37 + 0.26 AGE; $r=0.350, p<0.0001$.

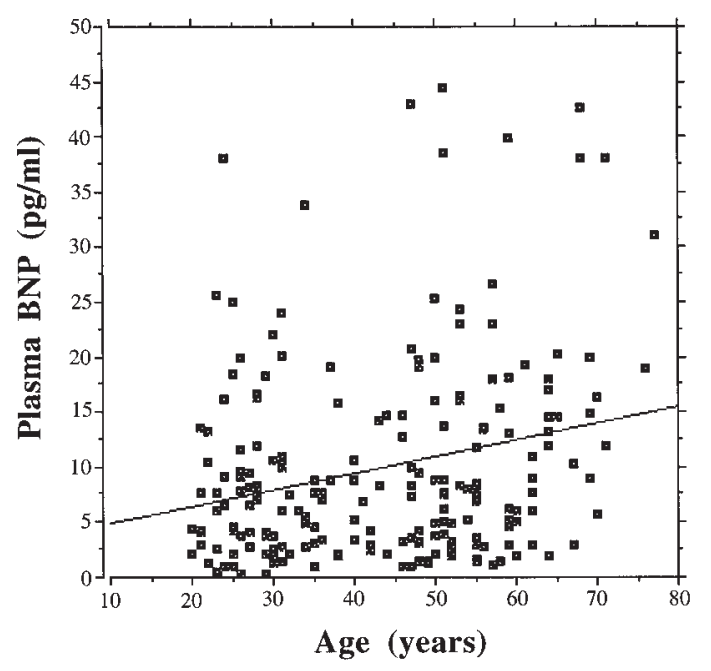

Figure 2 Linear relationship between plasma BNP levels and age in normal men and women. The calculated relationship was: $B N P=3.16+0.16$ AGE; $r=0.254, p=0.0002$.

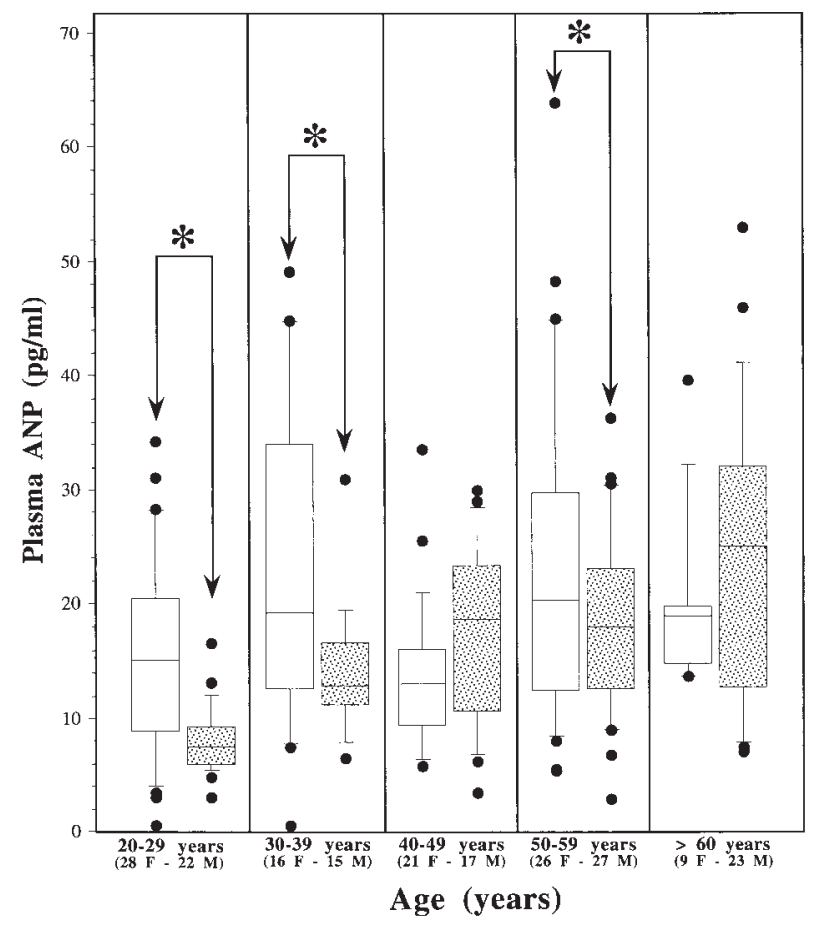

Figure 3 Mean $( \pm$ SEM) ANP values divided according to decade age groups and sex. The $p$-values $\left({ }^{*}\right)$ of significant difference $(p<0.05)$ between the age groups of women and those of men were tested by means of Fisher's protected least significant difference (PLSD) test after ANOVA ( $F=4.880$, $\mathrm{p}<0.0001$ ) using the logarithmic transformation of original set of data. The number of women ( $F$, empty square) and men (M, square filled with points) tested for each group was also indicated in parentheses. The results are expressed as boxes with five horizontal lines, displaying the 10th, 25th, 50th (median), 75th and 90th percentiles of the variable. All values above the 90th percentile and below the 10th percentile (outliers) are shown as solid circles.

0.5-64 pg/ml), without a significant difference between the mean value observed in men $(16.7 \pm 10.0 \mathrm{pg} / \mathrm{ml})$ and that found in women $(18.8 \pm 11.7 \mathrm{pg} / \mathrm{ml})$.

The mean BNP value in healthy adult subjects of 
both sexes was $9.9 \pm 9.0 \mathrm{pg} / \mathrm{ml}$ (median $7.6 \mathrm{pg} / \mathrm{ml}$, range $0.4-44 \mathrm{pg} / \mathrm{ml})$, with a significant difference $(\mathrm{p}<0.0001$, $t$-test after logarithmic transformation of original data) between the mean value observed in men $(7.7 \pm 7.0$ $\mathrm{pg} / \mathrm{ml})$ and that found in women $(12.2 \pm 10.2 \mathrm{pg} / \mathrm{ml})$.

There was a weak, although significant, positive linear relationship between age and either ANP (Figure 1) or BNP (Figure 2) values. To better stress the possible influence of age and sex on circulating levels of cardiac natriuretic peptides, we reported the ANP (Figure 3 ) and BNP (Figure 4) values of all subjects studied, divided according to sex and decades of age. ANP values showed a significant linear increase with age in males (linear regression equation $\mathrm{ANP}=-0.44+0.37 \mathrm{AGE} ; \mathrm{r}=0.567$, $p<0.0001)$, but not in women $(r=0.191, p=0.0536)$; furthermore, women showed significantly higher levels than men in the first two decades (age ranging from 20 to 39 years) (Figure 3). On the other hand, BNP values in women were on average higher than the respective values in men for each age-decade group (Figure 4); furthermore, a significant linear relationship was found between BNP values and age both in men (linear regression equation $B N P=0.79+0.15 A G E ; \quad r=0.331$, $\mathrm{p}=0.0004)$ and in women $(\mathrm{BNP}=4.0+0.20 \mathrm{AGE} ; \mathrm{r}=0.272$, $\mathrm{p}=0.0048$ ), respectively.

To better illustrate the possible influence of old age

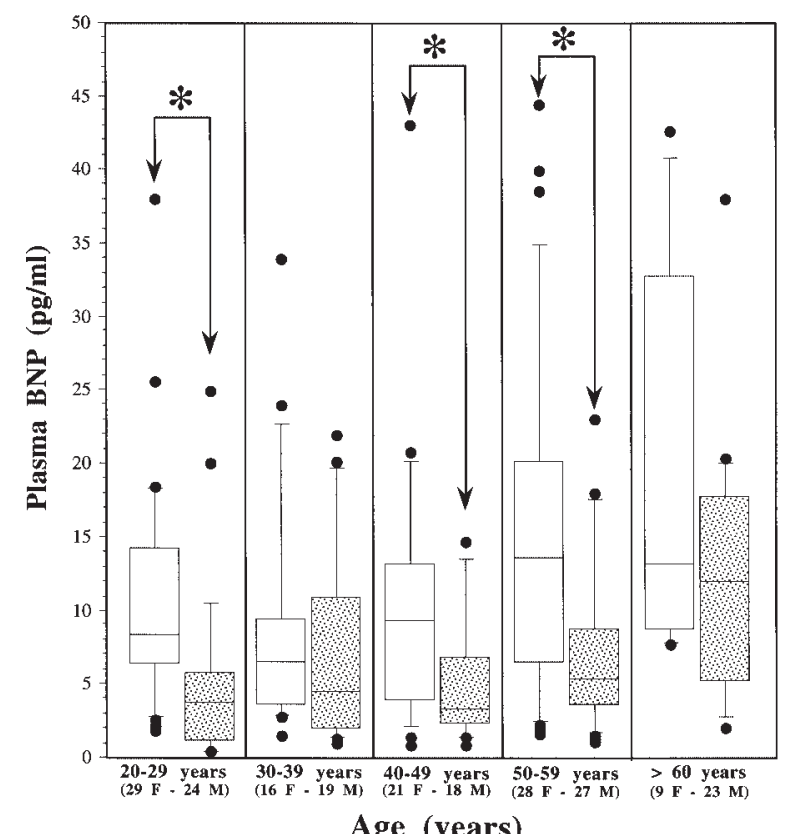

Figure 4 Mean $( \pm$ SEM) BNP values divided according decade age groups and sex. The $p$-values $\left({ }^{*}\right)$ of significant difference $(p<0.05)$ between the age groups of women and men were tested by means of Fisher's protected least siginificant difference (PLSD) test after ANOVA ( $F=6.218, p<0.0001)$ using the logarithmic transformation of original set of data. The number of women ( $F$, empty square) and men (M, square filled with points) tested for each group was also indicated in parentheses. The results are expressed as boxes with five horizontal lines, displaying the 10th, 25th, 50th (median), 75th and 90 th percentiles of the variable. All values above the 90th percentile and below the 10th percentile (outliers) are shown as solid circles.
Table 1 Circulating levels of ANP and BNP divided into four groups according to sex and age.

\begin{tabular}{llll}
\hline & Men & Women & p-Value* \\
\hline ANP $(p g / m l)$ & & & \\
Age $<50$ years & $12.8 \pm 6.9$ & $16.2 \pm 10.0$ & 0.2556 \\
Age $\geq 50$ years & $21.4 \pm 11.0$ & $22.9 \pm 13.1$ & 0.6243 \\
p-Value* & 0.0002 & 0.0012 & \\
BNP & & & \\
Age $<50$ years & $5.9 \pm 6.0$ & $10.0 \pm 8.3$ & $<0.0001$ \\
Age $\geq 50$ years & $10.1 \pm 7.8$ & $15.6 \pm 11.8$ & 0.0192 \\
p-Value* & 0.0001 & 0.0150 & \\
\end{tabular}

*Fisher's protected least significant difference (PLSD) test after ANOVA using the logarithmic transformation of original set of data. Means \pm SD are shown.

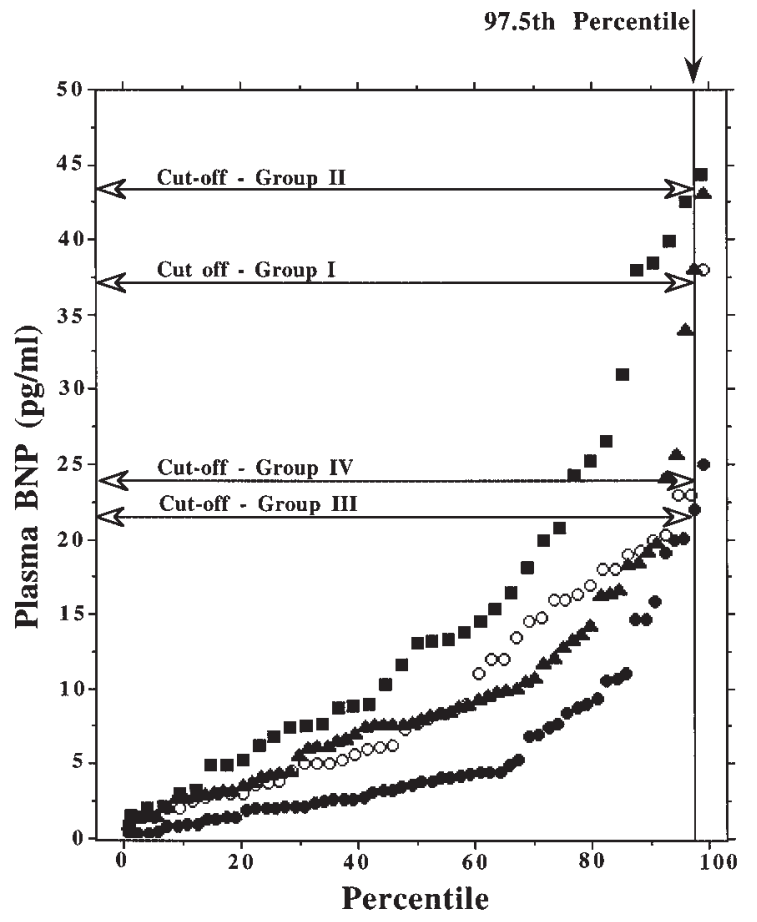

Figure 5 Cut-off values of plasma BNP, calculated as the 97.5th percentile of the distribution values in the four groups of studied subjects. Group I: women aged $<50$ years; Group II: women aged $\geq 50$ years; Group III: men aged $<50$ years; Group IV: men aged $\geq 50$ years. $\Delta$ I; $\mathbf{\square I} ; 0$ III; $\bigcirc$ IV.

and the effects of the decrease in female sex hormones after menopause, we divided the subjects into four groups according to age and sex (two groups included 61 men and 66 women aged $<50$ years; the other two groups included 47 men and 42 women aged $\geq 50$ years) (Table 1). The cut-off of 50 years was chosen because this value is usually considered to be the mean age of menopause, at least in the Western European countries (22).

ANOVA analysis of original data showed that there were significant differences $(p<0.0001)$ among the groups of subjects both for ANP and BNP values. In particular, ANP values were higher in men and women aged 50 years and more, while ANP values did not differ between men and women. These findings suggest 
that ANP levels may be more affected by age than by sex. On the other hand, BNP values were significantly higher in men and women aged 50 years and more. Furthermore, women showed significantly higher BNP levels compared to men at any age. These data suggest that BNP levels are greatly affected both by increasing age and by sex. It is also interesting to underline that highly different values were found if cut-off points were calculated as the 97.5th percentile from the distribution of plasma BNP values in these four groups of studied subjects (Figure 5).

Finally, when plasma ANP or BNP (considered as dependent variables) and age and sex (considered as independent variables) were analyzed by means of a multiple stepwise regression analysis, both age and sex significantly and independently contributed to the regression.

The multiple linear regression equations found for ANP and BNP, respectively were as follows:

Equation $1-\mathrm{ANP}=1.00+0.27 \mathrm{AGE}+3.23 \mathrm{sex}$ $(r=0.378, p<0.0001)$.

Equation $2-\mathrm{BNP}=-5.41+0.18 \mathrm{AGE}+5.24 \mathrm{sex}$ $(r=0.376, p<0.0001)$.

\section{Discussion}

Our study indicates that plasma concentration of cardiac natriuretic peptides increases with age and that women tend to have higher levels of plasma BNP than men. The increase in the circulating levels of both ANP and BNP with age was previously reported in other studies $(18,19)$. However, the contemporaneous effects of age and gender on the ANP/BNP system have been poorly investigated in the past. Our findings may be highly relevant to clinical practice and may also give original explanations concerning some pathophysiological mechanisms involved in cardiovascular disease.

The assay of circulating levels of ANP/BNP is usually used as a marker for myocardial function and, in particular, it is useful for the classification of patients with heart failure and/or for predicting their mortality/survival rates $(1-3,5)$. Heart failure is relatively rare in young adults, but in the Western countries the prevalence doubles with each decade after the age of 45 years $(20,23-25)$. Therefore, reference values for ANP/BNP assay should be given according to age and sex, by taking into account that the major part of patients with cardiovascular disease are older than 55 years (23-25) (Figure 5). On the other hand, some forms of heart disease (such as idiopathic dilated or hypertrophic cardiomyopathies) often occur in early adulthood, between 20 and 40 years of age. In this case, the use of appropriate reference values which would take into account the finding that circulating levels of cardiac natriuretic hormones are lower in early adulthood (especially in men) (Figure 4), could highly increase clinical sensitivity of BNP assay (Figure 5).

In order to explain the significant variation of circulating levels of cardiac natriuretic peptides with aging
(Figures 3 and 4), as well as the different patterns found in men and women, the effects of three distinct pathophysiological mechanisms should be taken into account.

1. The change of the cardiovascular system with aging. Such changes can induce dilatation of cardiac chambers (atria and/or ventricles) and/or hypertrophy of ventricle walls. These alterations should worsen progressively with aging by producing different stimulatory effects on ANP and BNP (see point 2 ) in both men and women. Heart rate declines and systolic blood pressure increases with increasing age $(26,27)$. In men, the decline in resting heart rate is compensated by an age-associated increase in resting cardiac volumes (i.e. end-diastolic, end-systolic and stroke volumes) $(26,27)$ so that systolic dysfunction is more often seen in men with an average age of about 60 years $(23,25)$. In contrast, resting cardiac volumes in healthy women vary less with aging than in men $(20,26)$, while diastolic dysfunction with concentric cardiac hypertrophy is more common in elderly women aged 70 years and older $(20$, $23,25)$.

2. The difference in production/secretion sites for ANP and BNP. ANP is predominantly produced and secreted in the atria in all conditions which induce stretching of the atrial wall, while BNP is preferentially produced and secreted in the ventricles after stretching of the ventricle wall $(1-3,5,23,27,28)$. Furthermore, BNP is generally considered to be a reliable and sensitive index of cardiac hypertrophy $(1-3,5,23,27,28)$, even without dilation of ventricles.

3. The possible effects of sex steroid hormones on the ANP/BNP system. Some studies suggest that female steroid hormones have a stimulating effect on the ANP/BNP system $(7,29)$. Evidently, the maximum effect should be observed in healthy menstruating women, with a progressive decrease after the menopause. Furthermore, the stimulatory action of female steroid hormones is probably greater on plasma BNP than ANP levels (29). Only scarse and very contradictory data have been reported on the action of male steroid hormones on the ANP/BNP system (7, 30-32).

The combined action of these three mechanisms may explain the different patterns of circulating levels of ANP and BNP found in both sexes throughout adult life. While the significant differences between cardiac natriuretic peptide levels of young adult men and menstruating women can be easily explained by the effect of female steroid hormones, it is more difficult to explain the sex differences in hormone levels after the menopausal age.

Taking into account the data reported in Figure 3 and Table 1, plasma ANP values were higher in healthy menstruating women compared to men of the same age, owing to the stimulatory effects of female steroid hormones. With menopause this stimulating action declines, but the effects produced by the alterations in the cardiovascular system induced by aging progressively increase by inducing a similar increase in ANP levels in both sexes. Our data suggest that women have a biphasic pattern of ANP throughout adult life with a de- 
cline between 40-49 years of age, probably because some women enter menopause at this age (Figure 3 ). On the contrary, a progressive linear increase of circulating levls of ANP was found in men (Figure 3 ).

Our findings also suggest that plasma BNP levels (Figure 4 and Table 1) were higher in healthy menstruating women than in men of the same age. After menopause the effect of steroid hormones declines but the increased thickness of interventricular septum and ventricular wall with aging, more frequent and accentuated in women $(20,23,25)$, may induce a progressive increase in BNP, greater in women. Consequently, women showed higher BNP values than men throughout adult life (Figure 4).

Many experimental studies in animals as well as observational studies in postmenopausal women have found a cardioprotective effect of estrogen treatment, with lower rates of coronary heart disease (7-9). Indeed, cardiovascular mortality in postmenopausal women receiving hormone replacement therapy is about $30-50 \%$ lower than in their untreated counterparts $(6-11)$. On the other hand, two recent clinical trials $(33,34)$ suggest a null-effect of hormone replacement therapy compared to placebo in women with prior history of myocardial infarction, coronary revascularization or angiographic evidence of coronary artery disease. However, the conclusions of these studies should not be extended to the majority of postmenopausal women presently undergoing hormone replacement therapy who usually have no symptoms of coronary artery disease and are on average younger than the women studied in these trials $(33,34)$.

The possible beneficial effects of female steroid hormones on the cardiovascular system may be more effective in the prevention of the atherosclerotic process, as suggested by the low incidence of cardiovascular events in normal menstruating women compared to men of the same age, as well as by its rapid increase in women after menopause. On the contrary, female steroid hormones may have little or no impact on irreversible atherosclerotic lesions, as demonstrated in the case of women enrolled in the two previously mentioned clinical trials $(33,34)$.

Cardiac natriuretic hormones have several important physiological actions with beneficial effects on cardiovascular disorders, including: a) a decrease in blood pressure; b) an increase in natriuresis and diuresis; c) an inhibition of the sympathetic nervous system activity and of the release or action of several hormones including aldosterone, angiotensin II, endothelins, renin and vasopressin $(1-3,27,28)$.

Therefore, it can be hypothesized that the cardioprotective actions of endogenous ovarian sex steroids during child-bearing years, or during hormone replacement therapy in postmenopausal women, may be mediated, at least in part, by increased circulating levels of cardiac natriuretic peptides $(7,29)$. Indeed, some experimental studies in animals suggest that steroid sex hormones significantly affect gene expression and production of cardiac natriuretic peptides (7). Furthermore, a recent study performed in our laboratory demonstrated that hormone replacement therapy in postmenopausal women increases the circulating levels of cardiac natriuretic hormones, especially those of BNP (29).

\section{References}

1. Sagnella GA. Measurement and significance of circulating natriuretic peptides in cardiovascular diseases [review]. Clin Sci 1998; 95:519-29.

2. Clerico A, lervasi G, Mariani G. Clinical relevance of the measurement of cardiac natriuretic peptide hormones in humans [review]. Horm Metab Res 1999; 31:487-98.

3. Clerico A, lervasi G, Del Ry S, Giannessi D. Immunoassay methods for the measurement of natriuretic cardiac hormones (ANP, BNP, and related peptides) in humans [review]. J Clin Ligand Assay 1999; 22:194-204.

4. Dzau VJ, Baxter JA, Cantin M, de Bold A, Ganten D, Gross $\mathrm{K}$, et al. Report of the Joint Nomenclature and Standardization Committee of the International Society of Hypertension, American Heart Association and the World Health Organization. J Hypertens 1987; 5:507-11.

5. Clerico A, Del Ry S, Giannessi D. Measurement of natriuretic cardiac hormones (ANP, BNP, and related peptides) in clinical practice: the need for a new generation of immunoassay methods [review]. Clin Chem 2000; 46:1529-34.

6. Maron DJ, Ridker PM, Pearson TA, Grundy SM. Dyslipidemia, other risk factors, and the prevention of coronary heart disease. In: Fuster V, Alexander RW, O'Rourke RA, Roberts R, King SB, Wellens HJJ, editors. Hurst's - the heart, 10th ed. New York: McGraw Hill; 2001:1131-60.

7. Kuroski de Bold ML. Estrogen, natriuretic peptides and the renin-angiotensin system. Cardiovasc Res 1999; 41:524-31.

8. Rosano GMC, Chierchia SL, Leonardo F, Beale CM, Collins P. Cardioprotective effects of ovarian hormones. Eur Heart J 1996; 17(Suppl D):15-9.

9. Sotelo M, Johnson RS. The effects of hormone replacement therapy on coronary heart disease. Endocrinol Metab Clin N Am 1997; 26:313-28.

10. Johnson SR. Menopause and hormone replacement therapy. Med Clin N Am 1998; 82:297-20.

11. Clinical Synthesis Panel on HRT. Hormone replacement therapy. Lancet 1999; 354:152-5.

12. Lakatta EG, Boluyt MO. Age-associated changes in the cardiovascular system in the absence of cardiovascular disease. In: Hosenpud JD, Greenberg BH, editors. Congestive heart failure, 2nd ed. Philadelphia: Lippincott Williams \& Wilkins, 2000:137-56.

13. Clark BA, Elahi D, Epstein FH. The influence of gender, age, and the menstrual cycle on plasma atrial natriuretic peptide. J Clin Endocrinol Metab 1990; 70:349-52.

14. Maffei S, Clerico A, lervasi G, Nannipieri M, Del Ry S, Giannessi $D$, et al. Circulating levels of cardiac natriuretic hormones measured in women during menstrual cycle. $\mathrm{J}$ Endocrinol Invest 1999; 22:1-5.

15. Clerico A, lervasi G, Del Chicca MG, Emdin M, Maffei S, Nannipieri $M$, et al. Circulating levels of cardiac natriuretic peptides (ANP and BNP) measured by highly sensitive and specific immunoradiometric assays in normal subjects and in patients with different degrees of heart failure. J Endocrinol Invest 1998; 21:170-9.

16. Jensen KT, Carstens J, Ivarsen P, Pedersen EB. A new, fast, and reliable radioimmunoassay of brain natriuretic peptide in human plasma; reference values in healthy subjects and in patients with different diseases. Scand J Clin Lab Invest $1997 ; 57: 529-40$. 
17. Del Ry S, Clerico A, Giannessi D, Andreassi MG, Caprioli R, lascone MR, et al. Measurement of brain natriuretic peptide in plasma samples and cardiac tissue extracts by means of an IRMA method. Scand J Clin Lab Invest 2000; 60:81-90.

18. Naruse M, Takeyama Y, Tanabe A, Hiroshige J, Naruse K, Yoshimoto $\mathrm{T}$, et al. Atrial and brain natriuretic peptides in cardiovascular diseases. Hypertension 1994; 23(Suppl 1): 1231-4.

19. Yoshibayashi M, Saito Y, Nakao K. Brain natriuretic peptide versus atrial natriuretic peptide - physiological and pathophysiological significance in children and adults: a review. Eur J Endocrinol 1996; 135:265-8.

20. Josephson RA, Fannin S, Rinaldi J. Physiology of the aging heart. In: Chesler E, editor. Clinical cardiology in the elderly, 2nd ed. Armonk (NY): Futura Publishing, 1999:51-77.

21. Clerico A, lervasi G, Del Chicca MG, Maffei S, Berti S, Sabatino $L$, et al. Analytical performance and clinical usefulness of a commercially available IRMA kit for the measurement of atrial natriuretic peptide in patients with heart failure. Clin Chem 1996; 42:1627-33.

22. Prior JC. Perimenopause: the complex endocrinology of the menopausal transition. Endocrine Rev 1998; 19:397-428.

23. Katz AM. Heart failure. Pathophysiology, molecular biology, and clinical management. Philadelphia: Lippincott Williams \& Wilkins, 2000:1-380.

24. Rich MW. Heart failure. Cardiol Clin 1999; 17:123-35.

25. Lindenfeld J, Krause-Steinrauf H, Salerno J. Where are all the women with heart failure? J Am Coll Cardiol 1997; 30:1417-9.

26. Friesinger GC. Cardiovascular disease in the elderly. Cardol Clin 1999; 17:35-49.

27. De Bold AJ, Bruneau BG, Kuroski de Bold ML. Mechanical and neuroendocrine regulation of the endocrine heart [review]. Cardiovas Res 1996; 31:7-18.

28. De Bold AJ, Bruneau BG. Natriuretic peptides. In: Fray JCS, editor. Handbook of physiology, section 7, volume III: endocrine regulation of water and electrolyte balance. Oxford : Oxford University Press, 2000:377-409.

29. Maffei S, Del Ry S, Prontera C, Clerico A. Increase in circulating levels of cardiac natriuretic peptides after hormone replacement therapy in postmenopausal women. Clin Sci 2001; 101:447-53.

30. Hwu CM, Tsai SC, Lau CP, Pu HF, Wang TL, Chiang ST, et al. Increased concentrations of atrial and plasma atrial natriuretic peptide in castrated male rats. Life Sci 1993; 52:205-12.

31. Deng $Y$, Kaufman S. The influence of reproductive hormones on ANF release by rat atria. Life Sci 1993; 53: 689-96.

32. Wu S, Weng X. Regulation of atrial natriuretic peptide, thromboxane and prostaglandin production by androgen in elderly men with coronary heart disease. Chin Med Sci J 1993; 8:207-9.

33. Hulley S, Grady D, Bush T, Furberg C, Herrington D, Riggs B, et al. [Heart and Estrogen/progestin Replacement Study (HERS) Research Group]. Randomized trial of estrogen plus progestin for secondary prevention of coronary heart disease in postmenopausal women. J Am Med Assoc 1999; 280:605-13.

34. Herrington DM, Reboussin DM, Brosnihan B, Sharp PC, Shumaker SA, Snyder TE, et al. Effects of estrogen replacement on the progression of coronary-artery atherosclerosis. N Engl J Med 2000; 343:522-9.

Received 3 September 2001, revised 4 February 2002, accepted 20 February 2002

Corresponding author: Aldo Clerico, MD, Laboratory of Cardiovascular Endocrinology, CNR Institute of Clinical Physiology, Via Trieste 41, 56126 Pisa, Italy Phone: +390503152682 / +390585 493569

E-mail: clerico@ ifc.pi.cnr.it 